\title{
Effect of Treatment with Diazoxide and Chlorothiazide on a Child with Leucine-sensitive Hypoglycaemia
}

\author{
D. B. GRANT,* M.B., M.R.C.P., D.C.H. ; A. T. PIESOWICZ,* M.B., M.R.C.P., D.C.H. \\ J. M. H. BUCKLER, ${ }^{*} \dagger$ B.M., M.R.C.P., D.C.H.
}

Brit. med. F., 1966, 2, 1494-1495

The hyperglycaemic effect of the benzothiadiazine diazoxide was recognized soon after the introduction of the drug in the management of hypertension (Dollery, 1962 ; Langdon and Wolff, 1962). It was subsequently shown that this hyperglycaemic effect was potentiated by thiazide drugs (Wolff and Parmley, 1963).

The use of diazoxide in the management of idiopathic leucine-sensitive hypoglycaemia has been described (Dollery, 1962 ; Drash and Wolff, 1964 ; Samols and Marks, 1966). We wish to report our findings in a child with idiopathic leucine-sensitive hypoglycaemia in whom treatment with diazoxide and chlorothiazide was followed by a reduced serum insulin response to both leucine and glucose.

\section{Case Report}

The patient, a girl aged 2 years and 11 months, was referred for investigation of convulsions, severe mental retardation, and recently discovered hypoglycaemia. Her perinatal and early history were normal until the age of 10 weeks, when she began to have frequent convulsions which were only partly controlled by various anti-

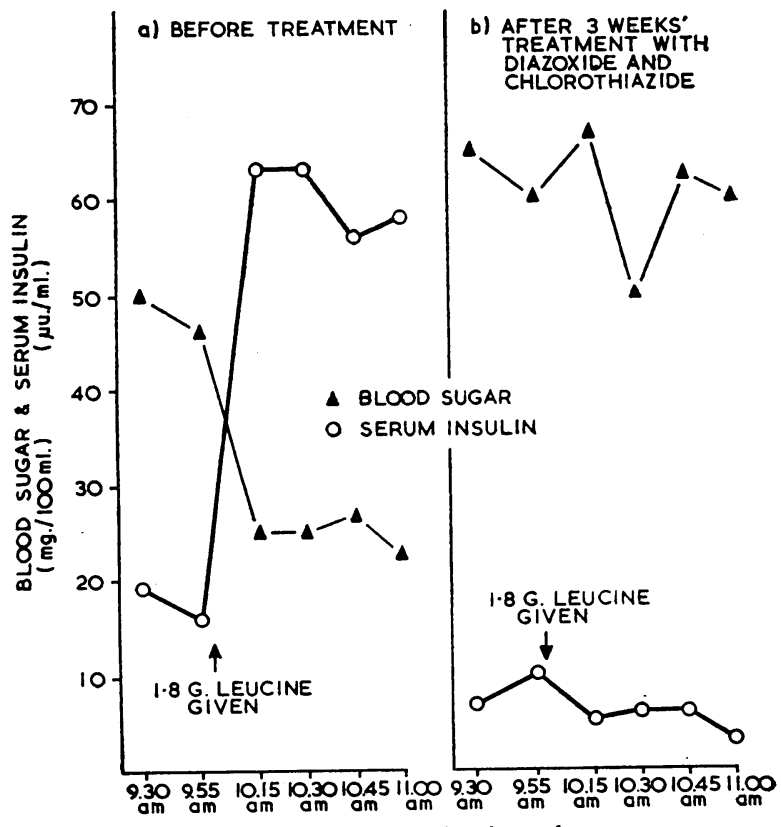

FIG. 1.-Results of the two leucine-tolerance tests.

convulsants. She showed little mental development after the onset of convulsions. On admission she weighed $12.3 \mathrm{~kg}$. She had athetoid spasticity and her mental development was at about the 6 months level.

The diagnosis of leucine-sensitive hypoglycaemia was made on finding a fall in blood sugar and a sustained rise in serum insulin after an oral leucine load (see Fig. 1). The clinical features and the initial insulin levels were thought to support the diagnosis of idiopathic leucine-sensitive hypoglycaemia rather than that of isletcell tumour. Pancreatic biopsy was not performed.

- The Hospital for Sick Children, Great Ormond Street, London. t Present address: Children's Hospital, Philadelphia.
The patient was given oral diazoxide in an initial daily dose of $5 \mathrm{mg}$./kg. body weight, divided into three equal doses. The dose of diazoxide was increased by stages (see Fig. 3) to $15 \mathrm{mg} . / \mathrm{kg}$., and after four weeks chlorothiazide $(16 \mathrm{mg} . / \mathrm{kg}$. body weight) was added to the treatment. Potassium supplements were not given.

During the latter part of the period of treatment the child's general condition improved. She gained $2 \mathrm{~kg}$. in weight over a period of two months, became more alert, and was less difficult to feed. On a daily dose of $120 \mathrm{mg}$. of phenobarbitone she had no further convulsions. Her blood pressure remained normal and no adverse side-effects were noted.

\section{Investigations and Results}

Capillary blood, obtained by finger-prick, was used for estimations of the blood sugar, serum insulin, and serum potassium. Values for the total blood sugar, determined by a modification of the method of Folin and Wu (Wilkinson, 1960), are given, as the true glucose level was not determined on all specimens. Insulin was estimated by a modified form of the immunoassay described by Morgan and Lazarow (1962), human insulin being used as a standard. The insulin determinations were repeated at the end of the period of study.

During the investigation the patient's daily diet was constant and contained $1,200 \mathrm{ml}$. of cows' milk. Her breakfast consisted of 170 $\mathrm{ml}$. of cows' milk (leucine content $=600 \mathrm{mg}$.) and $5 \mathrm{~g}$. of glucose.

Leucine-tolerance tests $(1.8 \mathrm{~g}$. L-leucine in $60 \mathrm{ml}$. of $0.01 \%$ Manoxal (dioctyl sodium sulphosuccinate)) and glucose-tolerance tests (16 g. of glucose in $160 \mathrm{ml}$. of water) were performed before treatment with diazoxide and after three weeks of treatment with diazoxide and chlorothiazide. The leucine was given through a nasogastric tube. All four tests began three hours after breakfast.

While treatment was being adjusted blood sugar and serum insulin were determined one and two and a half hours after breakfast.

The results of the two leucine-tolerance tests are shown in Fig. 1. In the first test the serum insulin rose from 16 to $63 \mu \mathrm{u} . / \mathrm{ml}$. and the blood sugar fell from 46 to $25 \mathrm{mg} . / 100 \mathrm{ml} .15$ minutes after the administration of leucine. In the second test there was no rise in the serum insulin and little change in the blood sugar.

The results of the two glucose-tolerance tests are shown in Fig. 2. In the first test the blood sugar rose from 44 to $104 \mathrm{mg} . / 100 \mathrm{ml}$. after 60 minutes and the serum insulin rose from an initial level of 58 to $99 \mu \mathrm{u} . / \mathrm{ml}$. after 30 minutes. In the second test the blood sugar rose from 32 to $200 \mathrm{mg} . / 100 \mathrm{ml}$. at 60 minutes and then fell to $40 \mathrm{mg}$. after a further 30 minutes. The serum insulin rose from 12 to $25 \mu \mathrm{u} . / \mathrm{ml}$. at 60 minutes.

The mean blood-sugar and serum-insulin levels one hour and two and a half hours after breakfast are shown in Fig. 3. On diazoxide alone there was no significant change in the mean seruminsulin levels, but after the introduction of chlorothiazide the mean insulin levels fell at both one hour $(P=0.01)$ and two and a half hours $(P=0.02)$.

After the introduction of diazoxide the mean blood-sugar level one hour after breakfast fell from 88 to $57 \mathrm{mg} . / 100 \mathrm{ml}$. $(P=0.01)$ but returned to the pre-treatment level after the addition of chlorothiazide. The mean blood-sugar level two and a half hours after breakfast showed a significant $(P=0.01)$ rise from 40 to $61.5 \mathrm{mg}$./ $100 \mathrm{ml}$. after the addition of chlorothiazide to the treatment.

There was no change in the level of the serum potassium during the period of investigation. 


\section{Discussion}

The mechanisms responsible for the diabetogenic action of diazoxide are still incompletely understood. There is, however, evidence that in man diazoxide inhibits the release of insulin after the administration of glucose (Dollery et al., 1962; Seltzer and Allen, 1965), and it has been shown that diazoxide inhibits the release of insulin in isolated rabbit pancreas incubated with glucose (Howell and Taylor, 1966). We were particularly interested to learn whether diazoxide could modify the marked rise in serum insulin which occurs after the administration of leucine in leucine-sensitive hypoglycaemia (Grum-

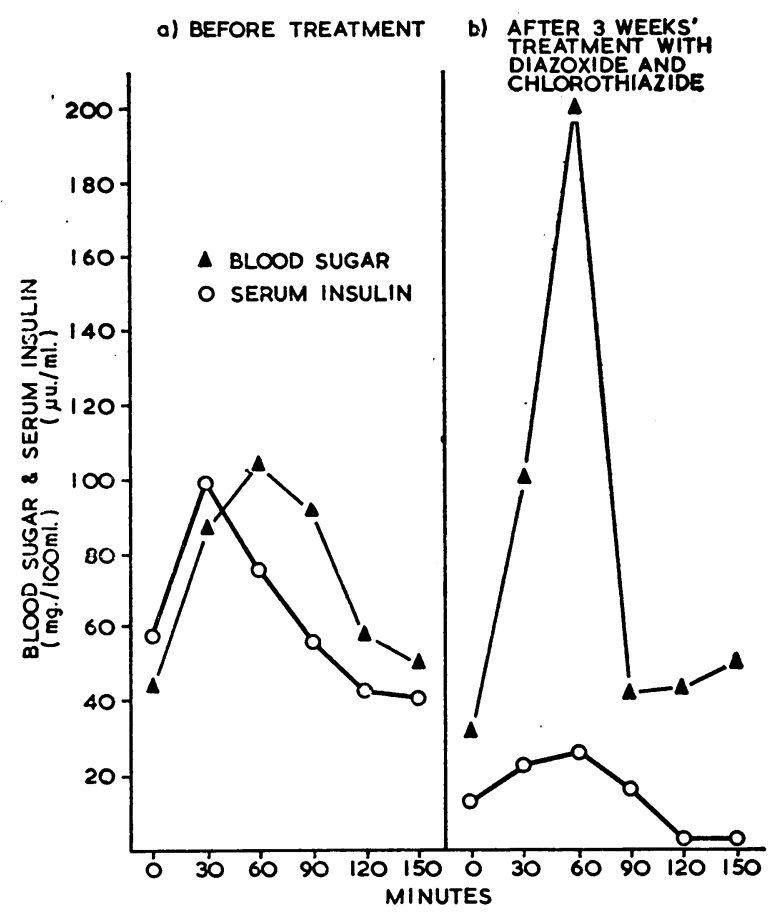

FIG. 2.-Results of the two glucose-tolerance tests.

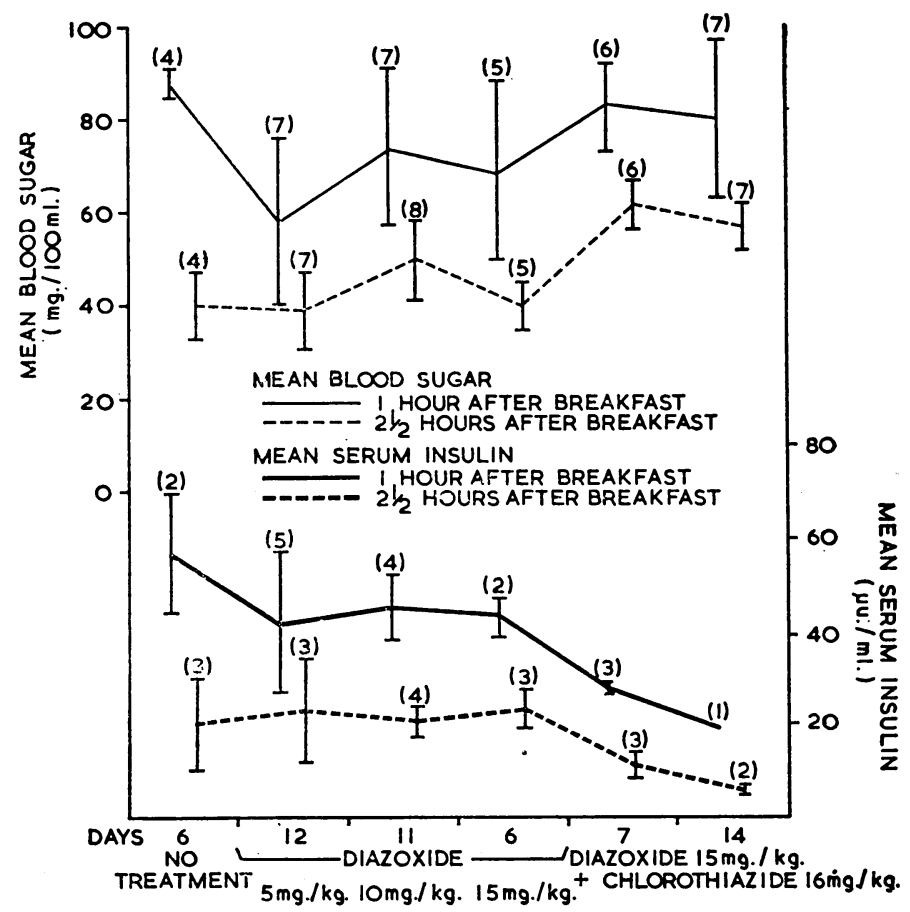

FIG. 3.-Mean blood-sugar and serum-insulin levels 1 hour and $2 \frac{1}{2}$ hours after breakfast. The number of estimations during each period of treatment is shown in parentheses. The vertical lines represent one standard deviation. The length of each period of treatment is shown at the foot of the figure. bach and Kaplan, 1960). The results of our investigations suggest that a combination of diazoxide and chlorothiazide inhibits the release of insulin after leucine, in addition to inhibiting the insulin response to glucose. These results are in agreement with the findings of Cornblath and Schwartz (1966), who reported the disappearance of leucine sensitivity in a patient after five months' treatment with diazoxide.

Treatment with diazoxide and chlorothiazide was followed by a rise in the mean blood-sugar level two and a half hours after breakfast, but this level was still lower than normal. This is unlikely to be due to continued leucine-induced insulin release, and is in keeping with the common finding in idiopathic leucine-sensitive hypoglycaemia of low fasting insulin levels. We are unable to explain the fall in the mean blood-sugar level one hour after breakfast which occurred on starting diazoxide, as the time of blood collection, the size of the breakfast, and the dose of phenobarbitone were constant during the period of investigation.

We believe that the patient is no longer leucine-sensitive, and we have not restricted the amount of leucine in her diet. As she has had only three months' treatment with diazoxide and chlorothiazide we are unable to assess the value of these drugs in the long-term management of her hypoglycaemia. There is little published information on the effects of prolonged administration of diazoxide in man, and we feel that its use must still be regarded as experimental.

We have recently seen a second leucine-sensitive child aged 4 years in whom treatment with diazoxide $(10 \mathrm{mg} . / \mathrm{kg}$. body weight) and chlorothiazide ( $20 \mathrm{mg}$. $/ \mathrm{kg}$. body weight) had to be discontinued after two weeks because of a drug rash. The next day she developed hyperglycaemia with ketosis which lasted for 24 hours and which required treatment with intravenous fluids.

ADDENDUM.-The patient has had two further leucinetolerance tests since this paper was submitted for publication. The first of these, after four months' treatment, confirmed the loss of leucine sensitivity. As it seemed possible that hypoglycaemia could be controlled by chlorothiazide alone, diazoxide was stopped for four weeks and a further leucine load given. This produced severe hvpoglycaemia with high serum insulin levels. Treatment with diazoxide was therefore restarted.

\section{Summary}

The effect of treatment with diazoxide and chlorothiazide on a child with idiopathic leucine-sensitive hypoglycaemia is described. This treatment appears to have inhibited the rise in serum insulin after the administration of leucine.

We wish to thank Sir Wilfrid Sheldon for permission to report this case and for his comments and advice; Dr. Barbara Clayton for her helpful criticism ; Dr. Philip Evans for drawing our attention to the second leucine-sensitive child; Dr. W. T. Simpson, of Allen \& Hanburys Ltd., for arranging the supply of diazoxide; Dr. Howard Smith, of the Wellcome Research Laboratories, for his gif: of a human insulin standard.

One of us (D B. G.) received financial support from the Medical Research Council, who also provided funds for the purchase of iodinated insulin.

\section{RBFERENCES}

Cornblath, M., and Schwartz, R. (1906). Disorders of Carbohydrate Metabolism in Infancy, p. 233. London.

Dollery, C. T (1962). Brit. med. f., 2, 337.

- Pentecost, B L., and Samaan, N. A. (1962). Lancet, 2, 735.

Drash, A., and Wolff, F. (1964). Metabolism, 13, 487.

Grumbach, M. M., and Kaplan, S. L. (1960). f. Pediat., 57, 346.

Howell, S. L., and Taylor, K. W. (1966). Lancet, 1, 128.

Howell, S. L., and Taylor, K. W. (1966). Lancet, 1, 128. 2,926

Langdon, R. G., and Wolf, F. W. (1962). Brit. med. F., 2, 926. 110, 29.

Samols, E., and Marks, V. (1966). Proc. roy. Soc. Med., 59, 811.

Seltzer. H. S., and Allen, E. W (1965). Diabetes, 14, 439

Wilkinson, R. H. (1960). Chemical Micromethods in Clinical Medicine, p. 68. Springfield, Illinois.

Wolff, F. W., and Parmley, W. W. (1963). Lancet, 2, 69. 